\title{
Neutral Argon Plasma in Minimally Invasive Medical Devices for Therapy ${ }^{\dagger}$
}

\author{
Jose A. Rodrigues *, Manuel F. Silva and J. H. Correia
}

CMEMS-UMinho, DEI, University of Minho, Campus Azurem, 4800-058 Guimaraes, Portugal; fsilva@dei.uminho.pt (M.F.S.); higino.correia@dei.uminho.pt (J.H.C.)

* Correspondence: id5730@alunos.uminho.pt; Tel.: +351-253-604703

+ Presented at the Eurosensors 2017 Conference, Paris, France, 3-6 September 2017.

Published: 11 August 2017

\begin{abstract}
This paper presents a solution to implement neutral argon plasma (NAP) in minimally invasive medical devices (MIMD) for therapy in endoscopy. The NAP system is composed by compressed inert gas (argon), two electrodes and a high-voltage source to ionize the argon. The miniaturization of an argon reservoir is required. The finite element method simulation of a small reservoir of $304 \mathrm{~L}$ stainless steel with $0.2 \mathrm{~mm}$ thick at $7 \mathrm{~atm}$ of pressure was performed. The results show maximum total deformation of $40 \mu \mathrm{m}$ and maximum equivalent stress of $160 \mathrm{MPa}$, with no permanent deformation of argon reservoir.
\end{abstract}

Keywords: argon plasma; therapy; actuator

\section{Introduction}

The research in minimally invasive medical devices (MIMD) have been growing in the last years. The appearance of new medical devices has allowed a better diagnosis and visualization of tissue until now not observed in a minimally invasive way. In endoscopy, for example, the endoscopic capsule has revolutionized the way of visualizing the gastrointestinal tract with painless visualization an access of the entire small bowel. Endoscopic capsules have evolved from passive diagnostic devices to active mobility systems with potential therapeutic capacity [1,2]. The latest developments in mobility of autonomous MIMD, with the possibility of stopping and rotating the MIMD, allow the integration of therapeutic techniques, such as the neutral argon plasma (NAP) [3]. Figure 1 envisages the integration of NAP in an autonomous MIMD.

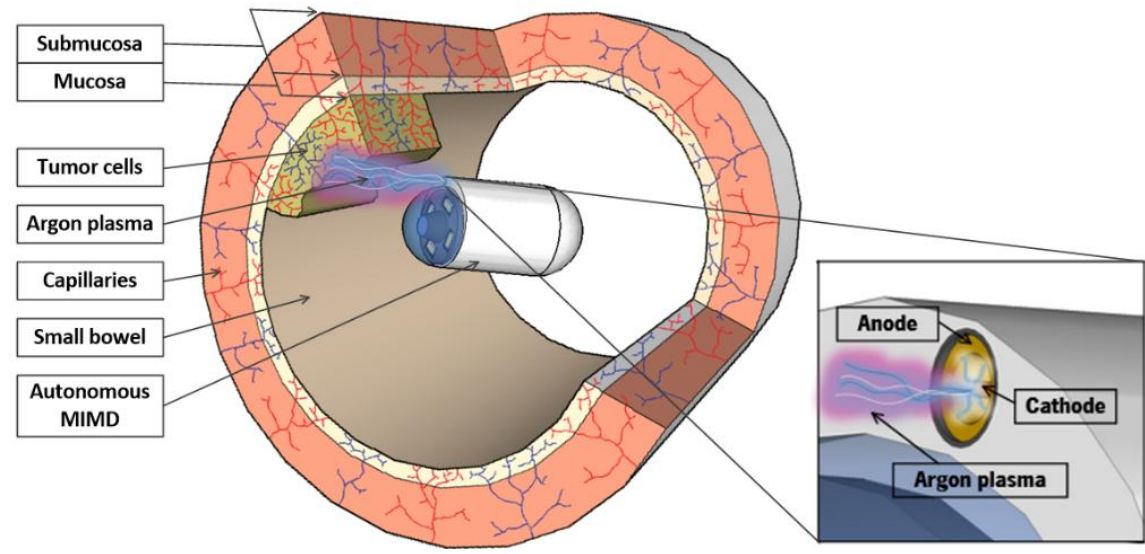

Figure 1. Illustration of the neutral argon plasma integrated in an autonomous minimally invasive medical device for therapy in small bowel (no access by traditional endoscopic instruments). 
Gas discharges in argon are growing in electrosurgery application, where they are used to induce mostly superficial thermal effects on tissue in a non-contact way. Argon plasma coagulation (APC) is a known monopolar electrosurgical technique in conventional endoscopy to coagulate and ablate tissue by applying argon discharges at atmospheric pressure [4,5]. Argon is used because it is biochemically inert, has a low breakdown voltage and is relatively inexpensive. Argon facilitates the arc of current between the target tissue and the active electrode (stainless steel or tungsten electrode, generally a wire), creating a low impedance zone through the air between the active electrode and the tissue. The distance between electrode and tissue is typically $2-10 \mathrm{~mm}$. An alternating voltage with an amplitude of typically $4 \mathrm{kV}$ and a frequency of $350 \mathrm{kHz}$ is used to ionize the flow of inert gas in a tube surrounding the electrode and to generate the effect on the tissue without contact [4].

NAP is a therapeutic technique similar to APC and bipolar electrosurgery that allows the tissue coagulation by the electrically neutral flow of ionized gas [6]. This technique uses an inert gas (argon) and a voltage around 30 to $60 \mathrm{~V}$ (applied between internal bipolar electrodes) to ionize the argon and produce high-energy electrically neutral plasma. The plasma has thermal, kinetic and light energy that allows the destruction of tumor tissue and blood at the application site. Subsequently, a small coagulum is formed which seals the surface of the tissue [6-8]. The depth of tissue penetration ranges from 0.5 to $2 \mathrm{~mm}$, depending on the application time of plasma in the tissue (1 to $3 \mathrm{~s}$ ). In contrast to electrosurgery techniques, the NAP has a remarkably gentle effect on tissue, minimizing the thermal damage to the underlying and adjacent tissues. This technique uses approximately $10 \%$ of the gas flow used in the APC. The gas flow is typically less than $0.4 \mathrm{~L} / \mathrm{min}$, reducing the risk of air embolism and intraperitoneal overpressure [6,7].

NAP is currently used in several surgical procedures including gynecology, surgical oncology, plastic surgery, thoracic surgery, hepatic and general surgery [8]. However, with this paper, we intend to introduce this technique in MIMD for therapy in endoscopy domain. A small argon reservoir is required to perform the NAP with MIMD. The following sections discuss the design and simulation of the argon reservoir.

\section{Materials and Methods}

The volume is one of the three state variables of gases, the others are the pressure and the temperature. The ideal gas law relates pressure, volume and temperature to the number of moles of the gas:

$$
\text { P.V = n.R.T, }
$$

where $\mathrm{P}$ is the gas pressure, $\mathrm{V}$ is the gas volume, $\mathrm{n}$ is the number of moles of the gas, $\mathrm{R}$ is the universal gas constant $\left(0.08206 \mathrm{~L} \cdot \mathrm{atm} \cdot \mathrm{mol}^{-1} \mathrm{~K}^{-1}\right)$ and $\mathrm{T}$ is the absolute temperature of the gas (in Kelvin). This law states that if the volume and temperature of a fixed amount of gas do not change, the pressure also remains constant [9].

Boyle's law says that if the temperature is kept constant, the volume of a given amount of gas is inversely proportional to the pressure, i.e., the product of pressure and volume is a constant [9]. For comparing the same substance under two different sets of conditions, the law is expressed by:

$$
P_{1} . V_{1}=P_{2} . V_{2} \text {, }
$$

where $P_{1}$ and $V_{1}$ represent the original gas pressure and volume, respectively, and $P_{2}$ and $V_{2}$ represent the gas pressure and volume of the second condition, respectively.

The gas flow used in the NAP technique is less than $0.4 \mathrm{~L} / \mathrm{min}$ or $6.67 \mathrm{~mL} / \mathrm{s}$. Assuming an argon flow of 3.3(3) $\mathrm{mL} / \mathrm{s}(0.2 \mathrm{~L} / \mathrm{min})$ during $1 \mathrm{~s}$, so the volume of argon used in the treatment will be 3.3(3) $\mathrm{mL}$ or $3333 \mathrm{~mm}^{3}\left(1 \mathrm{~atm}, 37^{\circ} \mathrm{C}\right)$. A pressure inside the argon reservoir of $7 \mathrm{~atm}$ and a temperature of $37^{\circ} \mathrm{C}$ were considered in the calculations of the argon reservoir volume. At the same temperature and maintaining the same amount of matter $(\mathrm{n})$, the volume of argon reservoir is:

$$
\mathrm{P}_{1} . \mathrm{V}_{1}=\mathrm{P}_{2} . \mathrm{V}_{2} \Leftrightarrow 1 \times 3333=7 \times \mathrm{V}_{2} \Leftrightarrow \mathrm{V}_{2}=476.1 \mathrm{~mm}^{3},
$$


So the volume of argon reservoir at a pressure of $7 \mathrm{~atm}$ to perform the NAP at $0.2 \mathrm{~L} / \mathrm{min}$ during $1 \mathrm{~s}$ is approximately $476 \mathrm{~mm}^{3}$. Figure 2 presents the dimensions of argon reservoir to implement inside the MIMD. The shape of argon reservoir matches with the current MIMD for endoscopy.

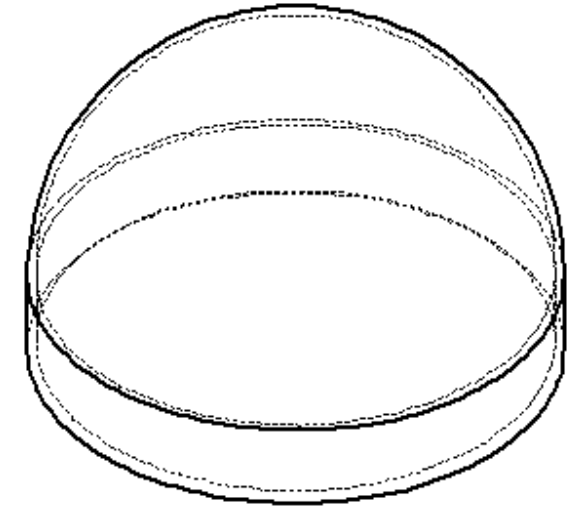

(a)

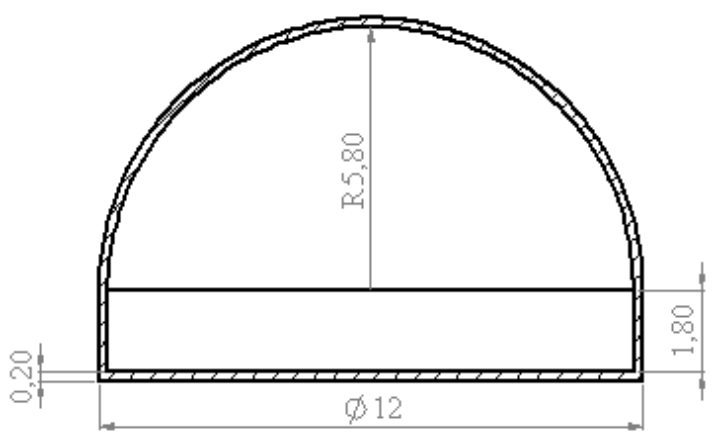

(b)

Figure 2. Dimensions of argon reservoir (mm): (a) isometric view; (b) cross-section view.

\section{Results}

The reservoir is composed by $304 \mathrm{~L}$ stainless steel corresponding to the properties of the American Society for Testing and Materials (ASTM) with $0.2 \mathrm{~mm}$ thick. The total mass of argon reservoir is approximately $642 \mathrm{mg}$. A finite element method (FEM) study of static analysis for pressure and temperature was performed to simulate the argon reservoir deformation. A mesh with default parameters was generated, with 2951 elements and 5898 nodes. A pressure inside the reservoir of $7 \mathrm{~atm}(709,275 \mathrm{~Pa})$ and an external temperature of $37^{\circ} \mathrm{C}$ (temperature inside the human body) was considered. Figure 3 presents the FEM results of total deformation and equivalent stress of argon reservoir.
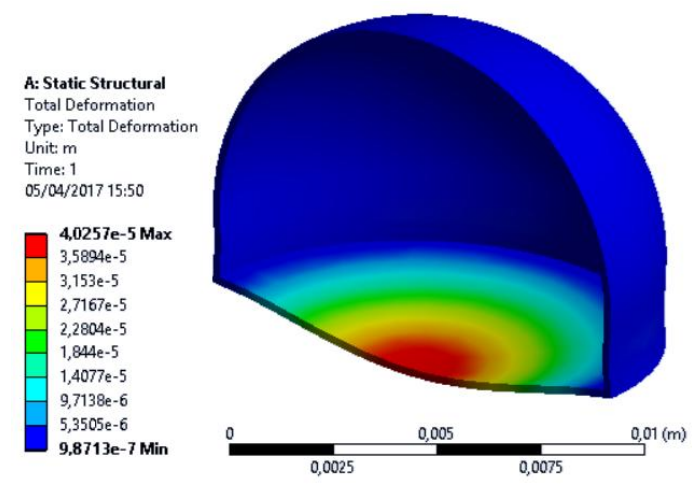

(a)

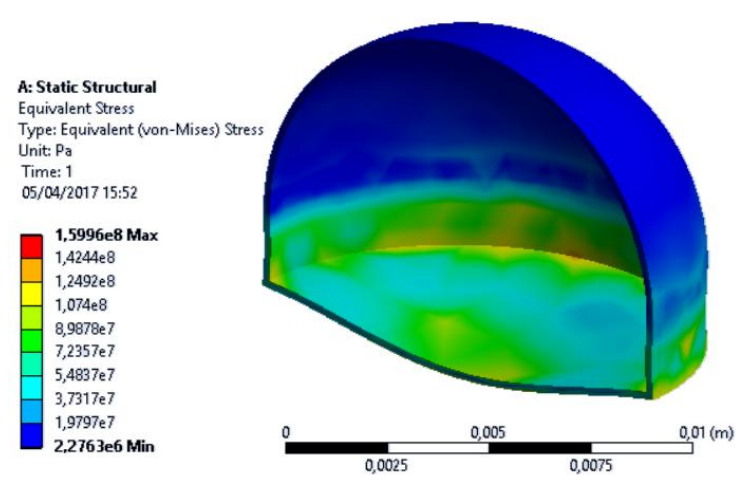

(b)

Figure 3. Simulation of $304 \mathrm{~L}$ stainless steel argon reservoir at 7 atm of pressure: (a) total deformation; (b) equivalent stress.

The maximum total deformation and maximum equivalent stress were approximately $40 \mu \mathrm{m}$ and $160 \mathrm{MPa}$, respectively.

A macroscale experimental setup was mounted to produce argon plasma. Figure 4 shows the neutral argon plasma arc when an electric discharge occurs between the two electrodes (separated by $5 \mathrm{~mm}$ with an argon gas flow of $1 \mathrm{~L} / \mathrm{min}$ ). 


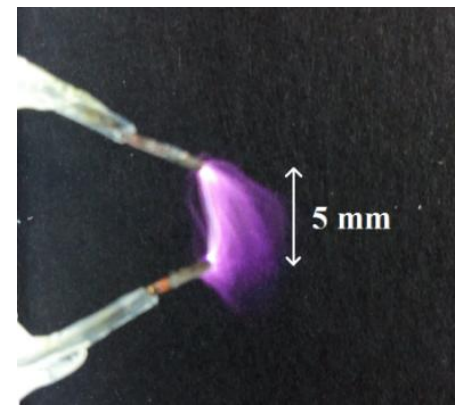

Figure 4. Neutral argon plasma arc when an electric discharge occurs between the two electrodes.

\section{Discussion}

The maximum equivalent stress $(160 \mathrm{MPa})$ is less than tensile yield strength of $304 \mathrm{~L}$ stainless steel $(207 \mathrm{MPa})$. The tensile yield strength point determines the performance limits of the material, since it represents the maximum stress that can be applied without permanent deformation. So, the reduced total deformation and the no induction of permanent deformation at the maximum equivalent stress, assure that the projected argon reservoir will withstand the pressure of $7 \mathrm{~atm}$ at $37^{\circ} \mathrm{C}$. The experimental results demonstrate the neutral argon plasma arc when an electric discharge occurs between the two electrodes. The integration of the NAP in MIMD will be a breakthrough for the new autonomous MIMD with therapy.

Acknowledgments: This work is supported by FCT with the reference project UID/EEA/04436/2013, by FEDER funds through the COMPETE 2020 with the reference project POCI-01-0145-FEDER-006941. Jose Artur Rodrigues is supported by FCT under grant SFRH/BD/103643/2014.

Conflicts of Interest: The authors declare no conflict of interest. The founding sponsors had no role in the design of the study; in the collection, analyses, or interpretation of data; in the writing of the manuscript, and in the decision to publish the results.

\section{References}

1. Iddan, G.; Meron, G.; Glukhovsky, A.; Swain, P. Wireless capsule endoscopy. Nature 2000, 405, 417, doi:10.1038/35013140.

2. Qureshi, W.A. Current and future applications of the capsule camera. Nat. Rev. Drug Discov. 2004, 3, 447-450, doi:10.1038/nrd1385.

3. Keller, J.; Fibbe, C.; Volke, F.; Gerber, J.; Mosse, A.C. Inspection of the human stomach using remote-controlled capsule endoscopy: A feasibility study in healthy volunteers (with videos). Gastrointest. Endosc. 2011, 73, 22-28, doi:10.1016/j.gie.2010.08.053.

4. Raiser, J.; Zenker, M. Argon plasma coagulation for open surgical and endoscopic applications: State of the art. J. Phys. D Appl. Phys. 2006, 39, 3520-3523, doi:10.1088/0022-3727/39/16/S10.

5. Ginsberg, G.G.; Barkun, A.N.; Bosco, J.J. The argon plasma coagulator. Gastrointest. Endosc. 2002, 55, 807-810, doi:10.1016/S0016-5107(02)70408-2.

6. Nezhat, C.; Kho, K.A.; Morozov, V. Use of Neutral Argon Plasma in the Laparoscopic Treatment of Endometriosis. J. Soc. Laparoendosc. Surg. 2009, 13, 479-483, doi:10.4293/108680809X12589998403967.

7. Madhuri, T.K.; Papatheodorou, D.; Tailor, A.; Sutton, C.; Butler-Manuel, S. First clinical experience of argon neutral plasma energy in gynaecological surgery in the UK. Gynecol. Surg. 2010, 7, 423-425, doi:10.1007/s10397-010-0591-2.

8. Gibson, P.F.; Suslov, N. The Effects of the PlasmaJet ${ }^{\circledR}$ System on Tissue; 2011. Available online: http://ltdwww.plasmasurgical.com/pdf/TissueStudy.pdf (accessed on 2 August 2017).

9. Ohanian, H.C.; Markert, J.T. The Ideal Gas. In Physics for Engineers and Scientists, 3rd ed.; Wiegman, L., Ed.; W.W. Norton \& Company, Inc.: New York, NY, USA, 2007; Volume 1, pp. 602-608.

(C) 2017 by the authors. Licensee MDPI, Basel, Switzerland. This article is an open access article distributed under the terms and conditions of the Creative Commons Attribution (CC BY) license (http://creativecommons.org/licenses/by/4.0/). 